This is the accepted version of an article published in the peer-reviewed journal Social Policy \& Administration 47(3), doi: 10.1111/j.1467-9515.2012.00851.x. For the version of record visit:

http://onlinelibrary.wiley.com/doi/10.1111/j.1467-9515.2012.00851.x/abstract

\title{
Addressing ethnicity in social care research
}

Tom Vickers, Gary Craig (both University of Durham) and Karl Atkin (University of York)

Correspondence address: Professor Gary Craig, SASS, University of Durham, 32 Old Elvet, Durham, DH1 3HN

email gary.craig@durham.ac.uk

tel. and fax. 01347848376 
This is the accepted version of an article published in the peer-reviewed journal Social Policy \& Administration 47(3), doi: 10.1111/j.1467-9515.2012.00851.x. For the version of record visit:

http://onlinelibrary.wiley.com/doi/10.1111/j.1467-9515.2012.00851.x/abstract

\title{
Addressing ethnicity in social care research
}

\author{
Abstract \\ This article surveys recent developments in relation to the dimensions of ethnicity and ethnic \\ disadvantage in social policy research and practice, with a focus on social care. While there \\ has been limited increase in attention to ethnicity within general policy discussion and \\ increasing sophistication within specialist debates, advances in theory and methodology have \\ largely failed to penetrate the mainstream of research, let alone policy or practice. We argue \\ for a more focussed consideration of ethnicity and ethnic disadvantage at all levels. Failure to \\ do so creates the risk of social policy research being left behind in understanding rapid \\ changes in ethnic minority demographics and patterns of migration, and increasing \\ disadvantage to minorities.
}

\section{Keywords}

'Race'; Racism; Social care; Health; Methodology; Diversity.

\section{Introduction}

Historically, where mainstream health and care forums have given attention to ethnicity, it has frequently been sidelined as a 'specialism', implying that it should not concern most researchers. There have, however, been indications that this view is changing, including attempts to develop specialist guidelines for reviewers of journal articles (Salway et al. 
This is the accepted version of an article published in the peer-reviewed journal Social Policy \& Administration 47(3), doi: 10.1111/j.1467-9515.2012.00851.x. For the version of record visit:

http://onlinelibrary.wiley.com/doi/10.1111/j.1467-9515.2012.00851.x/abstract

2009). This article draws on a commissioned review of research methods with Black and

Minority Ethnic (BME) populations in adult social care in England. Key objectives included:

- summarising the underlying methods of previous research;

- describing those methods, what contributions they have made, and what limitations or drawbacks might be associated with their use;

- reflecting on their use to date in social care practice studies; and

- making recommendations for whether and how these approaches might be more widely or more rigorously employed in research on social care practice in England.

This article focuses on findings from the review identifying areas where there is a need for research to respond more effectively to questions of ethnicity, including discussion of why health and care researchers need to be concerned with ethnicity, and how they can do so.

The review was conducted through an exploratory search of the literature, including online databases such as Web of Knowledge, Social Care Institute for Excellence, King's Fund, Race Equality Foundation, Ethnic Diversity in UK Social Research \& Public Policy Research, Information Centre About Asylum and Refugees and NHS Evidence: ethnicity and health. Where available, research briefings and reviews were also accessed to ensure full coverage. An invitation for contributory material was also circulated via online networks of researchers including the MINORITY-ETHNIC-HEALTH and SOCIAL POLICY academic jiscmail and other practitioner-oriented email lists. To this extent, our account is probably more akin to a knowledge review, providing a thematic, explanatory exploration of the relevant literature. Knowledge reviews are especially useful in informing a more reflexive policy and practice, when the evidence base is weak. 
Consequently, this article surveys current issues in social care with regard to ethnicity and considers the capacity of social care research to respond, drawing lessons also from recent health research developments and connecting empirical and theoretical themes. The limited nature of relevant literature makes our account partly speculative, but we hope it generates further discussion and suggestions for ways of overcoming the neglect of ethnicity in mainstream social care research. We begin by defining terms, reflecting broader theoretical discussion, which are often missing from mainstream debates, before moving to present more empirical findings.

\section{Why consider ethnicity in social care research?}

In terms of policy development and service delivery, the issue of 'race' continues to be overlooked in most areas of welfare provision within the UK (Craig et al. 2012). Within social care in particular, minority service users continue to experience services long failing to to provide equality of outcomes (Stuart 2012). However, at the level of basic scientific considerations, for evaluation of interventions to be generalizable to the wider population, they need to account for ethnic diversity, the more so given arguments for a thorough evidence base for policy and practice. Researchers need to be able to identify differential outcomes for different groups, understanding the interplay of biological, cultural, social, material, structural and other factors in contributing to these potential differences (Oakley 2006). Additionally, there are increasing expectations that health and social care research should include 'user perspectives', the definition of which has recently been expanded to include not only those directly accessing services but the public more generally, as people connected to users and as potential future users themselves (Dominelli and Holloway 2008). This requires including the experiences, needs and perspectives of ethnic minorities (Johnson 
This is the accepted version of an article published in the peer-reviewed journal Social Policy \& Administration 47(3), doi: 10.1111/j.1467-9515.2012.00851.x. For the version of record visit: http://onlinelibrary.wiley.com/doi/10.1111/j.1467-9515.2012.00851.x/abstract

2006). There is a need for research to be 'culturally competent', encompassing cultural awareness - including self-awareness, cultural knowledge, and cultural sensitivity - viewing participants as central partners in the research process (Papadopoulos 2006). This is reinforced by the need for: meaning to be accurately conveyed from participants to researchers; participants ' wider contexts to be understood; and researchers avoiding causing harm to participants or other members of the target group.

These scientific and ethical requirements are now underpinned by the Single Equality Act 2010, placing statutory responsibilities on researchers and employers to engage with ethnic diversity and to offer equal and fair treatment to all potential participants. The Act implies that research should not exclude ethnic minority populations by restricting its focus to people who, for example, speak English or, more generally, fail to recruit ethnically diverse samples, simply because of the inexperience of researchers working in multi-cultural settings. Race and religious belief are amongst seven protected characteristics requiring equal and fair treatment. By association, researchers have a public duty to promote equality and tackle discrimination. The impact of the Act on actual practice, although uncertain, creates further impetus for research, policy and practice to engage with ethnic diversity in a meaningful way, offering the opportunity to be used constructively as a catalyst for change.

\section{A context of rapid change and increasing diversity}

Building sophisticated consideration of ethnicity into research requires attention to a number of contextual spheres: super-diversity, inequality and racism (see Bulmer and Solomos 2004). In modern Britain, the competent handling of ethnicity in research requires understanding an 
This is the accepted version of an article published in the peer-reviewed journal Social Policy \& Administration 47(3), doi: 10.1111/j.1467-9515.2012.00851.x. For the version of record visit:

http://onlinelibrary.wiley.com/doi/10.1111/j.1467-9515.2012.00851.x/abstract

increasingly complex demographic picture. Britain has been multi-cultural to varying extents for centuries. Large-scale migrations from former colonies after the Second World War followed a variety of patterns across Britain, with differences in countries of origin, patterns of dispersal, predominant periods of arrival and links to local labour markets. These patterns of migration and their interaction with economic, legislative and other changes, continue to influence patterns of ethnic minority residence and experience today, although over 50 per cent of those defined as Indian, Pakistani, Bangladeshi, Black Caribbean and Black African populations have actually been born in Britain (Ahmad and Bradby 2007). Rapid demographic changes are occurring within these populations, with numbers of ethnic minority older people in the UK predicted to increase to 1.8 million by 2016 (Manthorpe $e t$ al. 2008).

This complex picture has been complicated further by new patterns of migration, including migrant workers from Central and Eastern Europe (Spencer et al. 2007), and refugees seeking asylum from many countries, from the 1990s onwards. A mapping exercise in York, hitherto regarded as a largely white Anglo-Saxon city, identified ninety-two different ethnic/national groupings, compared to six or seven in the early 1990s (Craig et al. 2010). Since 2004, increased immigration from Central and Eastern Europe has contributed to the conception of white ethnic minorities which has never hitherto been a strong feature of UK debates, despite the presence of, for example, Irish Catholics and Jews, in mainland Britain for centuries. The experience of disadvantage and discrimination for such groups is likely to be very different from that of established non-white ethnic minority populations.

Even for 'visible' minority groups long present in Britain, such as those of Chinese origin, serious experiences of racism have been neglected in both research and statutory responses, 
This is the accepted version of an article published in the peer-reviewed journal Social Policy \& Administration 47(3), doi: 10.1111/j.1467-9515.2012.00851.x. For the version of record visit:

http://onlinelibrary.wiley.com/doi/10.1111/j.1467-9515.2012.00851.x/abstract

partly due to the way statistics and other data are collected and presented. These struggle to respond to the more dispersed patterns of residence of the Chinese population (Chau 2008; Adamson et al. 2009). Similarly, the experience of Travelling and Gypsy communities has been marginalised, despite their presence in Britain for over 500 years (Matthews 2008), as has that of those of Irish origin. There is now a rapidly growing number of people who claim their ethnic origin as mixed-heritage; in parts of London, one in two children now born to a parent of African-Caribbean origin has a second parent from another ethnic group. The consequence of these developments is that the UK is now increasingly referred to as 'superdiverse' (Finney and Simpson 2009; Fanshawe and Skriskandarajah 2010), although the profile and magnitude of that diversity varies substantially between regions. This renders earlier understandings of ethnicity no longer relevant, suggesting the danger that social care research, historically slow to accommodate ethnicity, will be left behind.

\section{A context of inequality}

The UK may be a diverse society but socio-economic (and ethnic) inequalities in life chances and living standards show relatively few signs of narrowing (Audit Commission 2004; Hills 2010). Inequalities and concentrations of disadvantage associated with membership of particular minority ethnic groups are apparent in aspects of people's lives including socioeconomic status and types of employment (ONS 2006a; Clancy 2008; ONS 2008), levels of unemployment (WLRI 2005; Heath and Cheung 2006; ONS 2006b), arrests, convictions and sentencing (Goodman and Ruggiero 2008), general health and long-term limiting illness or disability (Butt 2006; Nazroo 2006) and access to welfare services (Craig 2007). 
This is the accepted version of an article published in the peer-reviewed journal Social Policy \& Administration 47(3), doi: 10.1111/j.1467-9515.2012.00851.x. For the version of record visit:

http://onlinelibrary.wiley.com/doi/10.1111/j.1467-9515.2012.00851.x/abstract

Within the context of such inequalities, aspects of identity and experience interact in specific, complex ways, and ethnicity needs to be understood in the much broader context of people's lives. For example, Anionwu and Atkin (2001) report how women of African-Caribbean and South Asian origins struggle to get consultant physicians to take their concerns seriously. If, however, this is contextualised in the broader literature, we find this is predominantly explained by gender relationships, rather than ethnicity. Nazroo and Karlsen (2009) caution against uncritically 'controlling out' socio-economic differences in order to 'isolate' variation with ethnicity or religion, arguing both that social and economic factors need to be considered together, and that research needs to address the way that religion and ethnicity become racialised alongside associated inequalities. The intersections between factors are important: in some cases these lead to cumulative disadvantage - the case with ethnicity and disability (Ali et al. 2006), or labour market participation and ill-health (Salway et al. 2007a). Among people of similar religious orientations there are gradations of likelihood of being in poverty for people differing in other respects: Muslims come to this country from, for example, Pakistan, Sudan, Malaysia and China, with differing economic (and cultural) backgrounds (Ansari 2009). Migration routes may also exert an influence alongside ethnic identity and national origin. For example, although asylum seekers and refugees have been few in number compared to other categories of migrants, they have experienced particular problems of destitution, increasing in recent years (Patel and Kelley 2006; Lewis et al. 2008). For some migrants, combinations of insecure or exploitative conditions of employment, migrant status, lack of recourse to public support, racism and increased insecurity and competition as a result of recession, can render their needs and experiences particularly 'invisible’ to policy and the service design (Wilkinson et al. 2009). 
This is the accepted version of an article published in the peer-reviewed journal Social Policy \& Administration 47(3), doi: 10.1111/j.1467-9515.2012.00851.x. For the version of record visit: http://onlinelibrary.wiley.com/doi/10.1111/j.1467-9515.2012.00851.x/abstract

\section{A context of racism}

Social care practice and research have operated within a context where implicit and explicit racism and the superiority of 'whiteness' are deeply embedded in Britain's past and present imperialist position (Young 2004). Despite the political success of national liberation struggles in Western colonies during the twentieth century, much of these countries' land and resources continue to be owned and/or exploited by Western multinational companies, Newly-independent states have been subject to an international economic system which undermines local control over their economic or development priorities (Kyriakides and Virdee 2003; Kundnani 2007). These international relationships between Britain and other countries are reflected in the treatment of those migrating to Britain, including provision of care. Craig (2007) discusses the history of Britain's welfare provision, in which the inclusion of British citizens in welfare entitlements has involved the simultaneous exclusion of noncitizens, and the needs of migrants have been subordinated to those of British labour markets. Despite a succession of policies under 'race relations', 'community relations', and now 'community cohesion' banners, an underlying racism in processes and outcomes continues, and health and social care professionals are increasingly called on by government to act as a second line of immigration control (Ahmad and Bradby 2007). Specific arguments used to justify such a discriminatory situation have been periodically reformulated in response to changing circumstances, most recently with the demonisation of Muslims by both government and media as part of the 'war on terror'.

This of course, raises questions of how we define 'racism'. 'Institutional racism' has recently become a popular explanation for public services' inability to respond to minorities' needs. In the UK context, this can be traced directly to the Macpherson Inquiry into the death of 
This is the accepted version of an article published in the peer-reviewed journal Social Policy \& Administration 47(3), doi: 10.1111/j.1467-9515.2012.00851.x. For the version of record visit: http://onlinelibrary.wiley.com/doi/10.1111/j.1467-9515.2012.00851.x/abstract

Stephen Lawrence (Macpherson 1999). Macpherson provided the term with moral authority, which found legal expression with the introduction of amendments to the Race Relations Act 1976 and the Equality Act 2010. Despite recent interest, institutional racism is not a new idea but has an international meaning. Institutional racism has emerged as an extremely helpful and productive idea in making sense of inequalities as well as inappropriate and inaccessible health and social care provision. It is this analytical legitimacy and the extent to which it captures the essence of ethnic discrimination that now concerns us. Making sense of this represents, for example, an important starting point in developing fertility support, sensitive to the needs of minority ethnic populations. At its most straightforward, institutional racism is often called camouflaged racism, meaning that it is not immediately obvious, but embedded in the taken-for-granted assumptions informing organizational practices. It occurs when the policies of an institution lead to discriminatory outcomes for minority ethnic populations, irrespective of the motives of individual employees of that institution. Institutional racism, in effect, is the uncritical application of policies and procedures, which ignore or misrepresent the needs of an ethnically diverse society (see Atkin 2009), finding various forms or expression.

In justifying Britain's international relations, culture and ethnicity have at times been assigned the significance of essential features of individuals, determining social attributes such as intellectual, moral or behavioural characteristics, providing a convenient diversion for the culpability of the powerful, by blaming the oppressed themselves (Ahmad and Bradby 2007). This has also impacted on many well-meaning efforts to address the needs of ethnic minorities, which have operated in ways which have contributed to reification - imputing a static and concrete existence to ethnic groups - and essentialization - ascribing ethnicity a fundamental and causal role within individuals. Within the health care field, it has been 
This is the accepted version of an article published in the peer-reviewed journal Social Policy \& Administration 47(3), doi: 10.1111/j.1467-9515.2012.00851.x. For the version of record visit: http://onlinelibrary.wiley.com/doi/10.1111/j.1467-9515.2012.00851.x/abstract

observed that research relating to minority ethnic populations is often marginalised as a 'speciality', whilst considerations of ethnicity are excluded from 'mainstream' studies and members of ethnic minority populations omitted from a large proportion of both clinical trials and qualitative studies (Atkin and Chattoo 2006; Hussain-Gambles 2003; McManus et al. 2006). Most 'peak' social policy and research journals publish little in this territory, whilst those papers published rarely reflect the experience of a multicultural society.

Mainstream service organisations have had a historical tendency to adopt a so-called 'colour blind'/'open door' approach which, by default, favours the majority white population. This comes to represent the 'norm' around which service delivery becomes organized (Atkin and Rollings 1993; Katz 2002). Service users are frequently assumed to have Western attitudes, priorities, expectations and values, to act according to Western ways, to speak English and understand the organisation of public services (Parekh 2006). Increasingly, as government policy now reverts back to 1960 s assimilationist policies, minorities and migrants alike are expected to behave as if they were white British people with darker skin colour: specific experiences relating to ethnicity and the context of racism are ignored (Gunaratnam 2003). It is therefore necessary to develop an understanding of ethnic disadvantage and migration which is contextual and international, as an antidote to the inadequacies of individualised models of anti-racist and anti-oppressive practice (Humphries 2004).

\section{Race, Culture and Ethnicity: The Politics of Identity}

One major theoretical problem facing those working in the area is the confusing range of terms used as part of these broader debates. In some ways it is difficult to impose consistent definition (Bulmer and Solomos 2004) and to do so would undermine the complexity of 
This is the accepted version of an article published in the peer-reviewed journal Social Policy \& Administration 47(3), doi: 10.1111/j.1467-9515.2012.00851.x. For the version of record visit: http://onlinelibrary.wiley.com/doi/10.1111/j.1467-9515.2012.00851.x/abstract

current debates. All this is perhaps not surprising, since ethnicity is a multi-faceted concept. This, although reflecting how people live their lives, can lead to analytical imprecision, frustrating policy and practice. Ethnicity is notoriously difficult to define and has come to embody a broad range of ideas, including language, religion, faith, culture, nationality and a shared heritage (see Bhopal 2007). Ethnicity is increasingly also understood politically, defining not just exclusion by a powerful majority but conversely also a source of pride and belonging; in other words a mobilizing resource, enabling minority ethnic populations to celebrate their difference and make legitimate demands as UK citizens (Morris 2007).

In terms of present policy discourses, ethnicity and 'race' are used interchangeably, assuming almost the same meaning. This is why 'race' is often presented in inverted commas, to demonstrate its constructed (and problematic) nature. The two categories, of course, imply each other and cannot be treated as mutually exclusive. Just as ethnicity evokes a sense of common heritage, kinship and descent, 'race' and racism are not only descriptive terms for physical difference but involve potent cultural metaphors and value judgments justifying negative/discriminatory attitudes. The idea of there being such distinct racial groups has of course become unsustainable, even though racism remains a pervasive theme of our social and political domains, sometimes evoking racial categories, while at other times emphasizing a form of cultural imperialism (Bulmer and Solomos 2004).

Hence, it is important to bear in mind that ethnicity, culture and community do not refer to fixed or essential characteristics that people 'have', but rather to dynamic processes of self-identity and differentiation involving negotiation of boundaries of inclusion and exclusion among groups (Bauman 2001). These boundaries are fluid and shift according to the context of social interaction, and struggles over power and resources over time (Hall 1996). Further, an individual's age, gender, faith, sexual orientation, disability and socioeconomic position, as well as how others respond to these dimensions of identity, mediate experience. In some contexts, these aspects of identity may be more 
This is the accepted version of an article published in the peer-reviewed journal Social Policy \& Administration 47(3), doi: 10.1111/j.1467-9515.2012.00851.x. For the version of record visit: http://onlinelibrary.wiley.com/doi/10.1111/j.1467-9515.2012.00851.x/abstract

important than ethnicity in making sense of a person's situation (Lo and Stacey 2008).The increasing interest in identity, therefore, offers possibilities for including ethnicity in more mainstream debates and in doing so, could offer a more nuanced approach to ethnicity, culture and 'race' (Atkin 2009). This potential has yet to be realized.

\section{Ethnic minorities in social care}

Relative disadvantage and discrimination for many minorities suggests high levels of need for care and support, yet historically social care provision has fared poorly in investigating, understanding and responding to these needs, and in many cases has added to the problems faced by minorities. Butt (2006) suggests that many service providers in the 1970s/80s either that ethnic minorities did not have particular needs for support, or that these needs were already met by their 'community', a view which still permeates - implicitly or explicitly much welfare practice. For example, when comparing by age and area of the country, UK ethnic minorities were already less represented in adult care homes in 1991, and decreased proportionally more than the white population by 2001, particularly in London. An association was demonstrated between this decrease and increasing volumes of care for older Asian people being carried out on an unpaid basis by someone living in the same house (Banks et al. 2006). Research by the National Black Carers and Workers Network (NBCWN 2008: 30) found that 'nearly one in five Pakistani women aged 30-pension age, and one in ten British Pakistani or Bangladeshi men aged 16-29, are also carers', these amongst some of the most deprived communities in Britain. This disadvantage seems likely to increase further, as the national trend is one of rising thresholds for entitlement to statutory support, yet BME carers have been given little attention within legislative and policy documents, with no explicit mention of these groups in any of the Carers Acts and only fleeting references within 
This is the accepted version of an article published in the peer-reviewed journal Social Policy \& Administration 47(3), doi: 10.1111/j.1467-9515.2012.00851.x. For the version of record visit: http://onlinelibrary.wiley.com/doi/10.1111/j.1467-9515.2012.00851.x/abstract

National Service Frameworks' (NBCWN 2008). Research identifies a serious lack of information of entitlements and services amongst ethnic minority people, even where there were no language barriers, with a particular lack of information amongst recent migrants (Chahal 2004; Newbigging and Lowe 2005; Craig et al. 2006). Even where responses to ethnic diversity in care provision have improved, take-up by ethnic minority people may therefore have declined partly because many people are unaware of what is available. Ironically, paid care work is heavily dependent on migrant workers who make up a fifth of all care workers looking after older people and 28 per cent of those recruited in 2007, many of them in extremely exploitative conditions (Hussein et al. 2010; Shutes 2012).

Specific issues of unmet needs amongst ethnic minorities in specific social care areas are too varied to be detailed, but include:

- the marginalisation of ethnic minority disabled people and white ethnocentrism in earlier forms of the social model of disability (Stuart 1992; Mir and Tovey 2003) and deaf culture (Ahmad et al. 2002; Praat et al. 2005)

- failure to understand the interaction of disablism with racism and consequent expectations that people prioritise one form of oppression they face (Vernon 2002: 2), with particular experiences of isolation for many disabled refugees (Roberts and Harris 2002; Patel and Kelley 2006); tensions reflected in current debates about personalization;

- ongoing 'colour-blindness' in mainstream mental health provision alongside damaging stereotypes associating black men with physicality, aggression, dangerousness (Newbigging et al. 2007) and associated disproportionate levels of coercive measures (Pinto et al. 2008). This operates alongside poor support for user consultation (Rai-Atkins et al. 2002) and inadequate funding for the BME voluntary 
This is the accepted version of an article published in the peer-reviewed journal Social Policy \& Administration 47(3), doi: 10.1111/j.1467-9515.2012.00851.x. For the version of record visit: http://onlinelibrary.wiley.com/doi/10.1111/j.1467-9515.2012.00851.x/abstract

and community sectors (Chahal 2004; Newbigging et al. 2007; Craig 2011).

- a lack of attention in research and practice to religious and cultural influences on needs and experiences in hospice and palliative care (Gunaratnam 2001; Jones 2003).

- little consideration of ethnic diversity, when considering self-care and personalised care debates. We also continue to know very little about ethnically diverse populations' relationship to welfare benefits (Salway et al. 2007b).

- the neglect of experiences of older people from minority populations and interrelationships of ethnic minority status, concentration in areas with high levels of deprivation, poverty, and lack of accessible and/or appropriate services (Craig et al. 2000; Yu 2000), with particular neglect of those living in rural areas (Manthorpe et al. 2008) and older refugees (Patel and Kelley 2006).

- an inability to provide sophisticated accounts of how ethnicity mediates experience and outcomes (Karlsen and Nazroo 2006) and a need to offer non-essentialized accounts of ethnic difference, incorporating other aspects of a person's identity such as gender, age, social class (Atkin 2009).

Butt (2006) summarises the main continuing barriers to adequate responses to ethnic diversity in care as: lack of knowledge amongst ethnic minorities of the availability of support; lack of appropriate, quality services; lack of choice; workers without effective communication skills; workers without the experience and skills needed to work with diverse communities; and direct and institutional racism. These play out differently within each type of social care. Butt argues that successfully promoting diversity and meeting the needs of minority service users requires not only avoiding perpetuating these barriers, but developing conscious strategies to overcome their effects (see also Chahal 2004; NBCWN 2008). 
This is the accepted version of an article published in the peer-reviewed journal Social Policy \& Administration 47(3), doi: 10.1111/j.1467-9515.2012.00851.x. For the version of record visit: http://onlinelibrary.wiley.com/doi/10.1111/j.1467-9515.2012.00851.x/abstract

\section{Lessons from health research}

Research in the health field has progressed further than in social care, offering important lessons. Ahmad and Bradby (2007) provides an overview of developments since the mid1990s which have increased the complexity and sophistication of definitions around ethnicity and racism, begun to address the relationship between ethnic and socioeconomic inequalities, explored questions of identity and meaning of health and care amongst ethnic minorities, and examined difference amongst and between different minority groups. Kelly et al. (2008) report on a study of the contribution of socioeconomic, maternal and behavioural factors to higher rates of low birthweight amongst ethnic minorities in the UK, associated with risk of chronic disease in later life, and challenge the acceptance, in an absence of causal understanding, that this ethnic difference is somehow 'normal'. Developing a wider variety of measures of socio-economic status than previously and a finer differentiation of ethnic groups, they suggest that socio-economic differences are a significant causal factor in ethnic differences in birth-weight (also Mallinson and Popay 2007).

Despite such advances, important gaps remain for particular groups in health research, and the growing sophistication in documenting and analysing racism and disadvantage has not been matched with a growing effectiveness in tackling it (Ahmad and Bradby 2007). An increase in the use of qualitative methods in health research in order to include the insights of minority perspectives has been criticised in some cases for being under-theorised and loosely inter-disciplinary, leading to poor contextualisation and much research that is not rigorous and little more than descriptive (Atkin and Chattoo 2006). 'Diversity' approaches, promoted in the name of overcoming one-dimensional views of oppression, and now given institutional backing with the incorporation of the Commission for Racial Equality into a new Equality 
This is the accepted version of an article published in the peer-reviewed journal Social Policy \& Administration 47(3), doi: 10.1111/j.1467-9515.2012.00851.x. For the version of record visit: http://onlinelibrary.wiley.com/doi/10.1111/j.1467-9515.2012.00851.x/abstract

and Human Rights Commission, have been criticised for diverting attention from the specific roots and processes of racism targeted by anti-racist approaches onto a generalised and power-blind 'anti-discrimination' approach (Butt 2006; Needham and Carr 2009). Despite the importance of locating ethnicity in relation to other key variables, such as gender, age and disability, there is now a renewed danger of ethnicity becoming 'lost'. How this tension is negotiated - and how ethnicity is reflected in research practice - will have considerable influence on future policy and practice, particularly since a recent survey identified a gap between the self-perceived competency of government departments in addressing questions of 'race' and ethnicity and other evidence which suggests continuing problems, including research which involves inappropriate conceptualisations of ethnic "groups"; fails to address issues of concern to minority ethnic people; lacks cultural competence; and fails to incorporate a broader social, historical and political analysis of ethnicity' (Barley and Salway 2009, and see discussion about identity above).

This reflects a much broader question, the conceptualisation of ethnicity, which tends to be represented as both fixed and homogenous, having the same meaning in all contexts for all defined as members of that minority group (Ahmad and Bradby 2007). This essentializing view of ethnicity has, as noted, been repeatedly challenged (Atkin and Chattoo 2007) by the view that not every aspect of a person's identity and experience - or of their health and encounters with the health care system - can be explained by his/her ethnic background. As among the 'white' population, a person's identity, like their health experiences and care encounters, are influenced by their age, gender and socio-economic position, as well as by how others respond to these different dimensions of identity. The key is to understand when ethnicity makes a difference and when it does not. Ethnic identity is not fixed or predefined, but has different meanings both for different people and for the same individual in different 
This is the accepted version of an article published in the peer-reviewed journal Social Policy \& Administration 47(3), doi: 10.1111/j.1467-9515.2012.00851.x. For the version of record visit:

http://onlinelibrary.wiley.com/doi/10.1111/j.1467-9515.2012.00851.x/abstract

situations. In some instances, a person may wish to emphasise religious identity; in others, gender or a sense of national heritage might be important. Equally, expressing one aspect of identity at the expense of another rarely reflects the way people live their lives; many people now live quite comfortably with a range of identities. The theoretical, methodological and empirical implications of such approaches have, however, yet to find their way into mainstream research, let alone policy and practice (Atkin 2009).

\section{Progress in social care research}

In social care there are more limited signs of progress, driven by a number of wider developments. High profile inquiries, such as those into the death of Stephen Lawrence or Zahid Mubarek, and, in the social care field, that of David Bennett, have combined with legislative developments, extending the remit for monitoring of ethnic inequalities from specialist bodies to organisations like the Commission for Social Care Inspection and the Audit Commission (Butt 2006). Examples such as Rai and Withey (2006) demonstrate the potential for well-designed local studies to provide valuable information on ethnicity and disadvantage, informing action for change. Important service user-led research has been undertaken by BME mental health survivors (Kalathil 2008). Yet much previous research continues to fail to impact on policy, practice and outcomes, despite years of research and discussion, leading to disillusionment among many ethnic minority people about involvement with research that doesn't seem to make a difference (Atkin 2003; Butt and O ’Neil 2004). This calls for greater attention to methodological issues, the quality of research practices, the relationship between 'specialist' research on ethnicity and the mainstream, and structural and institutional factors which prevent research findings from being fully acted on. The lack of improvements in practice may also reflect the way much of the research in the field has been 
This is the accepted version of an article published in the peer-reviewed journal Social Policy \& Administration 47(3), doi: 10.1111/j.1467-9515.2012.00851.x. For the version of record visit:

http://onlinelibrary.wiley.com/doi/10.1111/j.1467-9515.2012.00851.x/abstract

resourced and publicised, often conducted on a small scale for a local authority or other specific funder and remaining outside the horizons of many practitioners, service users, policymakers and academics, despite offering important insights (Brownfoot Associates 1998).

Even at the level of theoretical understanding, there remain significant gaps. For example, a major review found no evaluation directly comparing the benefits of different ways of organising mental health advocacy for African and Caribbean men. Of the organisations covered in the survey, engaged in forms of mental health advocacy, nearly one-third of mainstream advocacy organisations and many specialist BME organisations did not routinely record the ethnicity of users, severely limiting the potential for monitoring and the use of records for research (Newbigging et al. 2007).

Current trends show little sign of this changing. Barley and Salway (2009) report a telephone survey of a range of government social research departments and private research agencies on their self-reported procedures and competency in dealing with questions of 'race' and ethnicity, finding a patchy picture, reflecting one painted many years earlier (Rai 1995). In the absence of effective understanding and action against the specific roots of ethnic inequalities and racism - necessitating research employing a sophisticated understanding of ethnicity - the increasing focus in adult social care on 'co-production' of care involving users and their wider families and communities, holds the potential to deepen exclusion and deficient provision for some ethnic minority groups, absolving the state of responsibility (Needham and Carr 2009). Although significant differences associated with ethnicity are already apparent in the employment of personal budget schemes, including lower levels of engagement by ethnic minorities overall, differences in understandings of independent 
This is the accepted version of an article published in the peer-reviewed journal Social Policy \& Administration 47(3), doi: 10.1111/j.1467-9515.2012.00851.x. For the version of record visit:

http://onlinelibrary.wiley.com/doi/10.1111/j.1467-9515.2012.00851.x/abstract

living', difficulty finding personal assistants equipped to meet cultural, linguistic and

religious requirements of service users, and higher rates of employment of family members as

personal assistants, the specific use of personal budget schemes by ethnic minority people, and the relation of ethnicity to the personalisation agenda more broadly, has been underresearched (NBCWN 2008; Carr and Robbins 2009). For example, a scoping study by PSSRU into implementation of the personalisation agenda in four geographical areas included no built-in consideration of ethnicity (response to author's questions, workshop at the School for Social Care Research (an offshoot of the National Institute for Health Research) annual conference March 2010). Overall, capacity remains lacking in the main research centres to respond adequately to ethnically diverse populations in social care and most have little to say about ethnicity in their outputs.

\section{Discussion}

When doing research, important dilemmas face those attempting to reflect ethnic diversity. Methodologically, including more diverse samples is an obvious starting point. However, this is undermined if, having done this, researchers do not know how to make sense of the material or locate it within broader theoretical and empirical discussion. Researchers need carefully to reflect on the analytical relevance of recruiting more ethnically diverse samples, by thinking beforehand how they will use the data gathered. A broader literature is often available in which to contextualise empirical data on the experiences of a particular group and an important consideration can be to use this to explore similarities and differences among different ethnic groupings. 
This is the accepted version of an article published in the peer-reviewed journal Social Policy \& Administration 47(3), doi: 10.1111/j.1467-9515.2012.00851.x. For the version of record visit: http://onlinelibrary.wiley.com/doi/10.1111/j.1467-9515.2012.00851.x/abstract

There is a depressing familiarity to many issues raised here, some indeed longstanding problems, reflecting a deeper malaise about how we can translate good research evidence into practice, rather than constantly attempting to re-invent the wheel. The better-understood processes of disadvantage and discrimination can sometimes mislead those who are familiar with the complexity of current debates, into thinking that there is little else to do. Our growing awareness, however, has not always meant a more responsive welfare provision. The UK offers several examples of this. Empirical research has long discredited stereotypes of minority families who 'look after their own'. These ideas, however, as noted, continually surface in the attitudes of many practitioners (Craig et al. 2000; Atkin and Chattoo 2007).

Consequently, familiarity - evident in the work of some - is not always found in the research or practice of others. Essentialism has also long been discredited in academic circles, but is beginning to re-emerge, as research, policy and practice slowly adjust to the multicultural nature of society (Craig et al. 2012). Debates about the complex nature of ethnic identity seem ignored, as mainstream research, unfamiliar with previous debates, applies poorly contextualised ideas, reflected in equally poor research practice. The supposed fatalism of South Asian patients in discussing long-standing illness, for example, has become a common feature of the nursing and medical literature, with little recognition that fatalism does not preclude active engagement with the condition (Atkin and Ahmad 2000) or that fatalism can occur, irrespective of ethnicity, as people try to make sense of their situations (Chattoo and Ahmad 2004).

We need to take responsibility for our part in this, to be clear about the reasons, understandings and assumptions which underlay engagements with ethnicity, and the meaning of ethnic categories which we use. We need to keep in view at all times the complex 
This is the accepted version of an article published in the peer-reviewed journal Social Policy \& Administration 47(3), doi: 10.1111/j.1467-9515.2012.00851.x. For the version of record visit: http://onlinelibrary.wiley.com/doi/10.1111/j.1467-9515.2012.00851.x/abstract

and dynamic nature of ethnicity. Associations can be multiple, shifting and mediated by context. There is a constant interplay between different aspects of identity, with some experienced as more important and more supported (or more under threat) in some contexts than in others. As Salway points out, such a focus on the fluid and contingent nature of ethnicity does not necessarily sit easily with the stark divisions and inequalities social researchers attempt to understand (Salway et al. 2009). Research needs simultaneously to account for ethnicity's shifting nature and the very real and concrete impact of racism on people's experiences and outcomes. This requires turning away from culturalist explanations of inequality towards an understanding of the ways in which aspects of ethnic identity are realised, politicised and given material force through the process of social negotiation and dynamic power relationships. To this extent, the concern of research should not be to offer neat prescriptive cultural descriptions, purporting to explain and manage 'ethnicity', but to offer a more general discussion which contextualises diversity and difference, without recourse to simplistic explanations and naïve solutions, which then perpetuate disadvantage and discrimination.

At the same time, describing and documenting disadvantage creates a potential jeopardy. Constantly highlighting negative consequences of service provision can sometimes do little to advance thinking and practice, condemning everything while proposing nothing and creating a sense of inertia, making active engagement problematic. Policy and practice have not been particularly successful in translating research evidence, outlining the process and outcomes of discrimination, into tangible improvements in service delivery. As Taylor (1994) observes, to sustain multicultural societies, we need to develop 'the politics of difference' - in which there is a political commitment to ensuring diversity does not become the basis for inequality 
This is the accepted version of an article published in the peer-reviewed journal Social Policy \& Administration 47(3), doi: 10.1111/j.1467-9515.2012.00851.x. For the version of record visit: http://onlinelibrary.wiley.com/doi/10.1111/j.1467-9515.2012.00851.x/abstract

- rather than a narrow view of the 'politics of representation' - in which recognising difference becomes confused with responding to it.

At every stage of the research process, from commissioning, through developing methodological approaches, to dissemination, we need to recognise the ways in which a diversity of relationships - around racism, culture, religion, language, nationality, class, gender, disablism, life history, age, mental health, and sexuality - connect individuals, as part of groups, to wider contexts and processes up to an international level, in a two-way, dialectical process, in addition to reflecting this in outcomes and a commitment to tackling disadvantage and discrimination. 


\section{References}

Adamson, S., Chan, C-K., Cole, B., Craig, G. and Law, I. (2009) Hidden from public view? Racism against the UK Chinese population, London: The Monitoring Group/DCLG.

Ahmad, W. I. U. and Bradby, H. (2007) Locating ethnicity and health: exploring concepts and contexts', Sociology of Health \& Illness, 29: 795-810.

Ahmad, W. I. U., Atkin, K. and Jones, L. (2002) Being deaf and being other things: Young Asian people negotiating identities ', Social Science \& Medicine, 55: 1757-69.

Ali, N., Atkin, K., Craig, G., Dadze-Arthur, A., Elliott, C. and Edwards, A. (2006) Ethnicity, disability and the labour market, London: RNIB.

Anionwu, E. and Atkin, K. (2001) The Politics of Sickle Cell and Thalassaemia, Buckingham: Open University Press.

Ansari, H. (2009) The Infidel Within, London: Hurst and Co.

Atkin K. (2003) 'Ethnicity and the Politics of the New Genetics: Principles and Engagement', Ethnicity and Health, 8: 31-109.

Atkin K. (2009) Negotiating ethnic identities and health' in H. Graham (ed.), Understanding Health Inequalities, Maidenhead: Open University Press.

Atkin K, and Ahmad, W. I. U. (2000) Family care-giving and chronic illness: how parents cope with a child with a sickle cell disorder or thalassaemia', Health Soc. Care Community, 8: 57-69.

Atkin, K. and Chattoo, S. (2006) 'Approaches to conducting qualitative research in ethnically diverse populations', in J. Nazroo (ed.), Methodological Issues in Research Relating to Black and Minority Ethnic Groups: Publishing the evidence, London: Taylor \& Francis.

Atkin, K. and Chattoo, S. (2007) 'The dilemmas of providing welfare in an ethnically diverse state: seeking reconciliation in the role of a 'reflexive practitioner', Policy and Politics, 35: 377-93.

Atkin, K. and Rollings, J. (1993) Community Care in a Multi-Racial Britain: A Critical Review of the Literature, London: DoH.

Audit Commission (2004) The Journey to Race Equality: Delivering improved services to local communities, London: Audit Commission.

Banks, L., Haynes, P., Balloch, S. and Hill, M. (2006) Changes in Communal Provision for Adult Social Care 1991-2001, York: JRF.

Barley, R. and Salway, S. (2009) 'Social research for our multiethnic society: are UK researchers adequately trained and supported?', Social Research Association Newsletter, London: SRA.

Bauman, Z. (2001) Community: seeking safety in an insecure world, Cambridge: Polity Press.

Bhopal, R. (2007) Ethnicity, race and health in multicultural societies, Oxford: Oxford University Press.

Brownfoot Associates (1998) The needs of people with dementia and their carers within three ethnic minority groups in Haringey: London: Haringey Social Services Department/Alzheimer's Disease Society.

Bulmer, M. and Solomos, J. (2004) Researching race and racism, London: Psychology Press.

Butt, J. (2006) 'Are we there yet? Identifying the characteristics of social care organisations that successfully promote diversity', London: SCIE.

Butt, J. and O 'Neil, A. (2004) Black and minority ethnic older people's views on research findings, York: JRF.

Carr, S. and Robbins, D. (2009) 'The implementation of individual budget schemes in adult social care', London: SCIE. 
Chahal, K. (2004) Experiencing Ethnicity: Discrimination and service provision, York: JRF.

Chattoo, S. and Ahmad, W. I. U. (2004) 'The meaning of cancer: illness, biography and social identity', in D. Kelleher and G. Leavey (eds.), Identity and Health, London: Routledge.

Chau, R. C. M. (2008) 'Health experiences of Chinese people in the UK', London: Race Equality Foundation.

Clancy, G. (2008) 'Employment of foreign workers in the United Kingdom: 1997 to 2008', Economic and Labour Market Review, 2: 18-30.

Craig, G. (2007) '"Cunning, Unprincipled, Loathsome": The racist tail wags the welfare dog', Journal of Social Policy, 36: 605-23.

Craig, G. (2011) Forward to the past: does the Black and Minority Third sector have a future? Voluntary Sector Review, 2: 343-61.

Craig, G. with Kaur, S., Mumtaz, S. and Elliott-White, M. (2000) Giving Voice: Mapping older people's needs in Kirklees, Kirklees: Age Concern.

Craig, G., Adamson, S., Ali, N. and Demsash, F. (2010) Mapping rapidly changing minority ethnic populations: a case study of York, York: JRF.

Craig, G., Atkin, K., Chattoo, S. and Flynn, R. (eds.) (2012) Understanding 'race' and ethnicity, Bristol: Policy Press.

Craig, G., Dornan, P., and Bradshaw , J. (2006) Pensioner Poverty, London: National Audit Office.

Dominelli, L. and Holloway, M. (2008) Ethics and Governance in Social Work Research in the UK', British Journal of Social Work, 38: 1009-24.

Fanshawe, S. and Sriskandarajah, D. (2010) You can't put me in a box, London: IPPR.

Finney, N. and Simpson, L. (2009) Sleepwalking to segregation?, Bristol: Policy Press.

Goodman, A. and Ruggiero, V. (2008) 'Crime, Punishment, and Ethnic Minorities in England and Wales', Race/Ethnicity, 2: 53-68.

Gunaratnam, Y. (2001) "We mustn't judge people . . . but" staff dilemmas in dealing with racial harassment amongst hospice service users', Sociology of Health and Illness, 23: 6584.

Gunaratnam, Y. (2003), Researching Race and Ethnicity Methods, Knowledge and Power, London: Sage.

Hall, S. (1996), Introduction: who needs identity. In S. Hall and P. du Gay (eds), Questions of Cultural Identity, London: Sage.

Heath, A. and Cheung, S. Y. (2006) Ethnic Penalties in the Labour Market: Employers and Discrimination, London: DWP.

Hills, J. (Chair) (2010) Inequality in the UK, Report of the National Panel on Inequality, London: Government Equalities Office.

Humphries, B. (2004). 'An Unacceptable Role for Social Work: Implementing Immigration Policy.' British Journal of Social Work (34): 93-107.

Hussain-Gambles, M. (2003) 'Ethnic minority under-representation in clinical trials: Whose responsibility is it anyway?', Journal of Health Organization and Management, 17: 13843.

Hussein, S., M. Stevens and J. Manthorpe (2010) 'International Social Care Workers in England: Profile, motivations, experiences and future expectations', London: Social Care Workforce Research Unit, King's College.

Johnson, M. R. D. (2006) Engaging communities and users: Health and social care research with ethnic minority communities', in J. Nazroo (ed.), Health and Social Research in Multiethnic Societies, Abingdon: Routledge. 
Jones, K. (2003) Diversities in Approach to End-of-Life: A view from Britain of the qualitative literature, Leicester: Mary Seacole Research Centre.

Kalathil, J. (2008). Dancing to our own tunes: reassessing black and minority ethnic mental health service user involvement. Sutton: Survivor Research.

Karlsen, S and Nazroo, J. (2006) Defining and measuring ethnicity and race: theoretical and conceptual issues for health and social care research' in Nazroo, J. (ed.), Health and Social Research in Multiethnic Societies, London: Routledge.

Katz, A. (2002) Thwarted Dreams: Young Views from Bradford, London: Young Voice Project.

Kelly, Y., Panico, L., Bartley, M., Marmot, M., Nazroo, J. and Sacker, A. (2008) Why does birthweight vary among ethnic groups in the UK? Findings from the Millennium Cohort Study', Journal of Public Health, 31: 131-7.

Kundnani, A. (2007) The End of Tolerance: Racism in 21st Century Britain, London: Pluto Press.

Kyriakides, C. and Virdee, S. (2003) Migrant labour, racism and the British National Health Service', Ethnicity and Health, 8: 283-305.

Lewis, H., Craig, G., Adamson, S. and Wilkinson, M. (2008) Refugees, asylum seekers and migrants, Leeds: Yorkshirte Futures.

Lo, M. M. and Stacey, C. L. (2008), Beyond cultural competence: Bourdieu, patients and clinical encounters, Sociology of Health and Illness, 30: 741-55.

Macpherson, W., Sir (1999), Report into the death of Stephen Lawrence, London: The Stationery Office.

Mallinson, S. and Popay, J. (2007) Describing depression: ethnicity and the use of somatic imagery in accounts of mental distress', Sociology of Health \& Illness, 29: 6, 857-71.

Manthorpe, J., Harris, J. and Lakey, S. (2008) Strategic Approaches for Older People from Black and Minority Ethnic Groups, London: Better Government for Older People.

Matthews, Z. (2008) 'The health of Gypsies and Travellers in the UK', London: Race Equality Foundation.

McManus, S., Erens, B. and Bajekal, M. (2006) 'Conducting surveys among ethnic minority groups in Britain', in J. Nazroo (ed.), Health and Social Research in Multiethnic Societies, Abingdon: Routledge.

Mir, G. and Tovey, P. (2003) 'Asian Carers' Experiences of Medical and Social Care: The case of cerebral palsy', British Journal of Social Work, 33: 465-79.

Morris, E. W. (2007), Researching race: Identifying a social construction through qualitative methods and an interactionist perspective, Symbolic Interaction, 30: 409-25.

Nazroo, J. Y. (2006) 'Demography of multicultural Britain ' in J. Nazroo (ed.), Health and Social Research in Multiethnic Societies, Abingdon: Routledge.

Nazroo, J. and Karlsen, S. (2009) 'Religion, ethnicity and health inequalities' in H. Graham (ed.), Understanding Health Inequalities, Maidenhead, Open University Press.

National Black Carers and Workers Network (NBCWN) (2008) Beyond We Care Too: Putting Black Carers in the Picture, London: NBCWN.

Needham, C. and Carr, S. (2009) 'Co-production: an emerging evidence base for adult social care transformation', London: SCIE.

Newbigging, K. and Lowe, J. (2005) Direct payments and mental health. York: JRF.

Newbigging, K., McKeown, M., Hunkins-Hutchinson, E. A., French, B., with Habte-Mariam, Z., Coleman-Hill, L., Mullings, D., Stephens, A. and Holt, K. (2007) Mtetezi: Developing mental health advocacy with African and Caribbean men, London: SCIE. 
Oakley, A. (2006) 'Ethnicity and research evaluating health interventions: Issues of science and ethics' in J. Nazroo (ed.) Health and Social Research in Multiethnic Societies. Abingdon: Routledge.

Office for National Statistics (ONS) (2006a) 'Focus on Ethnicity and Identity: Employment Patterns', retrieved 28th October 2009 from http://www.statistics.gov.uk/cci/nugget.asp?id=463.

Office for National Statistics (ONS) (2006b) 'Focus on Ethnicity and Identity: Labour Market', retrieved 28th October 2009 from http://www.statistics.gov.uk/cci/nugget.asp?id=462.

Office for National Statistics (ONS) (2008) Employment of Foreign Workers: Focus on Earnings, London: ONS.

Papadopoulos, I. (2006) 'Culturally competent research: A model for its development.' in J. Nazroo (ed.), Health and Social Research in Multiethnic Societies, Abingdon: Routledge.

Parekh, B. (2006) Rethinking Multiculturalism: Cultural Diversity and Political Theory, Basingstoke: Palgrave Macmillan.

Patel, B. and N. Kelley (2006) 'The social care needs of refugees and asylum seekers', London: SCIE.

Pinto, R., Ashworth, M. and Jones, R. (2008) 'Schizophrenia in black Caribbeans living in the UK: an exploration of underlying causes of the high incidence rate', British Journal of General Practice, 58: 429-34.

Praat, A. and Barker, M. with Craig, G. and Atkin, K. (2005) Disability and Ethnicity: Black and minority ethnic groups with sensory disabilities in the labour market: A literature review, Hull: University of Hull/RNIB.

Rai, D. K. (1995) In the Margins: Current practices in qualitative social research with Asian communities, Hull: University of Humberside.

Rai, D. and J. Withey (2006) 'Newham Household Panel Survey (NHPS). Wave 4 report: poverty, employment, health, housing, quality of life, social capital, young people'. London: London Borough of Newham.

Rai-Atkins, A., with A. A. Jama, A. A., Wright, N., Scott, V., Perring, C., Craig, G. and Katbamna, S. (2002) Best Practice in Mental Health: Advocacy for African, Caribbean and South Asian communities, York: JRF.

Roberts, K. and Harris, J. (2002) Disabled People in Refugee and Asylum Seeking Communities, Bristol: Policy Press.

Salway, S., Allmark, P., Barley, R., Higginbottom, G., Gerrish, K. and Ellison, G. T. H. (2009) 'Social research for a multiethnic society: an exploration of current guidance and future possible directions' 21 st Century, 4: 53-81.

Salway, S., Platt, L., Chowbey, P., Harriss, K. and Bayliss, E. (2007a) Long-term ill health, poverty and ethnicity, York: JRF.

Salway, S., Platt, L., Harriss, K. and Chowbey, P. (2007b) Long-term health conditions and Disability Living Allowance: exploring ethnic differences and similarities in access', Sociology of Health and Illness, 29: 907-30.

Shutes, I. (2012), The employment of migrants in long-term care, Journal of Social Policy, 41: 43-61.

Spencer, S., Ruhs, M., Anderson, B. and Rogaly, B. (2007) Migrants' lives beyond the workplace: The experiences of Central and East Europeans in the UK, York: JRF.

Stuart, O. W. (1992) 'Race and disability: Just a double oppression?', Disability \& Society, 7: $177-88$.

Stuart, O.W. (2012) Not invited to the party? in Craig et al. (2012) op. Cit. 
This is the accepted version of an article published in the peer-reviewed journal Social Policy \& Administration 47(3), doi: 10.1111/j.1467-9515.2012.00851.x. For the version of record visit:

http://onlinelibrary.wiley.com/doi/10.1111/j.1467-9515.2012.00851.x/abstract

Taylor, C. (1994) Multiculturalism: examining the politics of recognition. Princeton: Princeton University Press.

Vernon, A. (2002) User-defined outcomes of community care for Asian disabled people, Bristol: Policy Press.

Wilkinson, M., Craig, G. and Gaus, A. (2009) Turning the Tide, Oxford: Oxfam.

Working Lives Research Institute (WLRI) (2005). Women refugees - from volunteers to employees: a research project on paid and unpaid work in the voluntary sector and volunteering as a pathway into employment. London: WLRI.

Young, R. J. C. (2004) White Mythologies, London: Routledge.

Yu, W. K. (2000) Chinese Older People: A need for social inclusion in two communities. Policy Press: JRF. 